\title{
DIABETIC FOOT ULCER- ROLE OF DIABETIC NEUROPATHY AND POOR GLYCAEMIC CONTROL ON OUTCOME
}

\author{
Manju Singh ${ }^{1}$, Gambhir Singh ${ }^{2}$, Amit Agrawal ${ }^{3}$ \\ 1 Professor, Department of Surgery, Pt. JNM Medical College, Raipur. \\ 2 Professor and HOD, Department of Surgery, RIMS, Raipur. \\ ${ }^{3}$ Assistant Professor, Department of Surgery, Pt. JNM Medical College, Raipur.
}

ABSTRACT
BACKGROUND
A diabetic foot ulcer is a poorly healing ulcer caused by a combination of effects of diabetes - neuropathy and vascular involvement.
Its related problems occur frequently and have serious consequences. Amputations at different level are most serious of them.

\section{MATERIALS AND METHODS}

A cross-sectional study was conducted in patients with such presentations. Data was collected in 96 such patients including detailed history and examination by simple random selection.

\section{RESULTS}

The results showed multifactorial risks including diabetes-induced neuropathy as significant factor $(\mathrm{p}=<0.05)$ along with poor glycaemic control and structural deformities showing significant effect.

\section{CONCLUSION}

These findings were quite promising and showed various risk factors involved. We also know that diabetics who undergo amputations are more likely to die and suffer further amputations. It also provides a useful database for starting a preventive foot care program and separate wound clinic for reduction in diabetic foot related morbidity and mortality.

\section{KEYWORDS}

Poor Glycaemic Control, Distal Symmetrical Neuropathy, Structural Deformity, Raipur Chhattisgarh.

HOW TO CITE THIS ARTICLE: Singh M, Singh G, Agrawal A. Diabetic foot ulcer- role of diabetic neuropathy and poor glycaemic control on outcome. J. Evolution Med. Dent. Sci. 2017;6(3):161-162, DOI: 10.14260/Jemds/2017/39

\section{BACKGROUND}

The World Health Organisation (WHO) defines diabetic foot as the lower limb of a diabetic patient that has the potential risk of pathologic consequences including infection, ulceration and/or destruction of deep tissues associated with neurologic abnormalities, various degrees of peripheral vascular disease and/or metabolic complications of diabetes. ${ }^{1}$

Diabetes and foot problems are almost synchronous. Neuropathy, infection, deformity and ischaemia are major threat to diabetics. Amputations are perhaps the most feared complications. Foot ulceration and amputations affect the quality of life of patients and create an economic burden for both patient and health care system. Diabetes is a lifelong problem and incidence of diabetic foot increases with age and duration of disease. The complications of diabetic foot ulcer consists of infection, gangrene, septicaemia, loss of limbs, osteomyelitis which greatly limit lifestyle of the patient and his family. This is very well categorised in Meggitt Wagner classification.

Financial or Other, Competing Interest: None.

Submission 02-12-2016, Peer Review 26-12-2016,

Acceptance 02-01-2017, Published 09-01-2017.

Corresponding Author:

Dr. Amit Agrawal,

HIG, C/72, Shailendra Nagar,

Raipur-492001,

Chhattisgarh.

E-mail: doc.amitagrawal@gmail.com

DOI: $10.14260 /$ jemds $/ 2017 / 39$

\section{(c) $(7)(-$}

\begin{tabular}{|c|c|}
\hline Grade 0 & No ulcer \\
\hline Grade 1 & Superficial skin ulcer \\
\hline Grade 2 & $\begin{array}{c}\text { Deep ulcer extension into ligament, tendon, } \\
\text { joint capsule, fascia. Bone may be exposed. No } \\
\text { abscess or osteomyelitis }\end{array}$ \\
\hline Grade 3 & $\begin{array}{c}\text { Deep ulcer with abscess or osteomyelitis or } \\
\text { joint sepsis }\end{array}$ \\
\hline Grade 4 & Gangrene to portion of forefoot or heel \\
\hline Grade 5 & Extensive gangrene of foot \\
\hline \multicolumn{2}{|c|}{ Table 1. Meggitt Wagner Classification ${ }^{2}$} \\
\hline
\end{tabular}

\section{Aim of Study}

1. To identify risk factors presenting with diabetic foot.

2. To evaluate association of identified risk factors with the complication of diabetic foot ulcer.

\section{MATERIALS AND METHODS}

A cross-sectional study was carried out in 96 patients with diabetic foot attending the surgical OPD and casualty of Dr. BRAM Hospital, Raipur (CG) and admitted consequently to surgical wards were included between September 2014 and August 2015. Data were collected including particulars of patient, detailed history and examination. Wound is graded according to Meggitt Wagner's classification system. Inclusion criteria include all adults above 18 years having diabetic foot ulcer and patients having neuropathic and ischaemic foot ulcer secondary to diabetes mellitus. Exclusion criteria includes foot ulcer secondary to venous disorders and arterial disorders other than diabetes mellitus and foot ulcers secondary to other causes of peripheral neuropathy like syringomyelia, etc. 


\section{RESULTS}

The mean age group of patients presenting with diabetic ulcer was 51.9 years. The male:female ratio was $2: 1$. It was found that $30.2 \%$ of patients required amputation. Associated risk factors are shown in table below. The patient with diabetic neuropathy (30.2\%) had high incidence of gangrene
(55\%) along with those with poor glycaemic control (24\%) had gangrene in (65\%). Smokers (39.5\%) developed gangrene in $29 \%$ of cases, while hypertension and structural deformities developed gangrene in $31 \%$ of cases.

\begin{tabular}{|c|c|c|c|c|c|}
\hline $\begin{array}{c}\text { Risk } \\
\text { Factors } \\
\end{array}$ & $\begin{array}{c}\text { Total No. } \\
\text { of Cases (a) }\end{array}$ & Gangrene & $\begin{array}{c}\text { No. of } \\
\text { Cases (b) }\end{array}$ & $\begin{array}{c}\% \\
(b / a)\end{array}$ & $\begin{array}{l}\% \text { of Total Involved out } \\
\text { of } 96 \text { Patients in Study }\end{array}$ \\
\hline \multirow{2}{*}{ Diabetic Neuropathy } & \multirow{2}{*}{29} & Present & 16 & 55 & 16.66 \\
\hline & & Absent & 13 & 45 & 12.5 \\
\hline \multirow{2}{*}{ Hypertension } & \multirow{2}{*}{10} & Present & 5 & 50 & 5.20 \\
\hline & & Absent & 5 & 50 & 5.20 \\
\hline \multirow{2}{*}{ Smoking } & \multirow{2}{*}{38} & Present & 11 & 29 & 11.45 \\
\hline & & Absent & 27 & 71 & 28.12 \\
\hline \multirow{2}{*}{ Poor Glycaemic Control } & \multirow{2}{*}{23} & Present & 15 & 65 & 15.62 \\
\hline & & Absent & 8 & 35 & 8.33 \\
\hline \multirow{2}{*}{ Structural Deformities } & \multirow{2}{*}{45} & Present & 14 & 31 & 14.58 \\
\hline & & Absent & 31 & 69 & 32.29 \\
\hline
\end{tabular}

\section{DISCUSSION}

Total of 96 patients of diabetic foot were enrolled in the study, out of which $42.7 \%$ were in age group of $45-60$ years. These findings were similar to those of Pecoraro et al. ${ }^{3}$ The gender distribution male:female was 2:1. This in contrast to other studies in Western world (Stepha L et al 1.27:1) ${ }^{4}$ has marked male preponderance. This is due to prevailing social circumstances, majority of smokers are males, females usually work indoors and reporting to the hospitals is less.

In this study, diabetic foot complications were multifactorial. The diabetic neuropathy $(30.2 \%)$ and poor glycaemic control (24\%) are significant factors along with hypertension and structural deformities contributing to them. Studies conducted by Abott $\mathrm{A}$ et $\mathrm{al}^{5}$ and some other standard studies show neuropathy in $(11 \%-20 \%)$ patients presenting with diabetic foot complications. The high number of patients presenting with neuropathy is due to delay in diagnosis of both diabetes and foot lesions. Diagnosed diabetics with neuropathy had uncontrolled disease either due to inadequate treatment or they were defaulters. Thus, neuropathy and even vasculopathy is accelerated in these patients. Poor diabetic status at the time of presentation is another important predictor for poor outcome in diabetic foot patients as also showed by Young PJ et al. ${ }^{6}$

Structural deformities were present in $46.87 \%$ of patients in this study. Studies in United States by Ronald et al ${ }^{7}$ showed $78 \%$ of patients with deformities in patients with diabetic foot complications. The reason is that among patients who have lost protective sensation due to polyneuropathy, most common mechanism seems to be unperceived, excessive and repetitive pressure on the sites of foot deformities. This leads to elevated focal pressure making ulceration even more likely. Some patients also present with metallic foreign bodies in the wound. The study also showed that smoking and hypertension also are predictors of development of complications in diabetic foot complications. This is also shown in studies conducted by Forrest et al. ${ }^{8}$ The results indicate that along with good glycaemic control, avoidance of smoking and normal blood pressure are helpful in preventing polyneuropathy in diabetics.

\section{CONCLUSION}

The above study shows that average age of presentation in diabetic foot complication is 51.9 years, so utmost care should be taken of limbs from $4^{\text {th }}$ till $6^{\text {th }}$ decade of life. Males are more prone to develop diabetic foot complications as compared to females. Most significant risk factors leading to diabetic foot complications are polyneuropathy and structural foot deformities complimented by smoking and hypertension. This study's findings are quite promising and show various associated risks leading to complications of diabetic foot. As we know the patients who underwent amputations due to diabetic foot complications are more likely to undergo amputation of other limb and also die; this study provides a useful database for starting a foot care program for reduction of diabetic foot related mortality and morbidity.

\section{REFERENCES}

[1] WHO/IDF. Definitions and diagnosis of diabetes and intermediate hyperglycemia. 71/2. World Health Organistion 2006.

[2] Treece KA, Macfarlane RM, Pound N, et al. Validation of a system of foot ulcer classification in diabetes mellitus. Diabet Med 2004;21(9):987-91.

[3] Pecoraro RE, Reiber GE. Classification of wounds in diabetic amputees. Wounds 1990;2:65-73.

[4] Hill SL, Holtzman GI, Buse R. The effects of peripheral vascular disease with osteomylitis in the diabetic foot. The American Journal of Surgery 1999;177(4):282-6.

[5] Abbott JD, Huang Y, Liu D, et al. Stromal cell derived factor $1 \alpha$ plays a critical role in stem cell recruitment to the heart after myocardial infarction but is not sufficient to induce homing in the absence of injury. Circulation 2004;110(21):3300-5.

[6] Young MJ, Veves A, Walker MG, et al. Correlations between nerve fuction and tissue oxygenation in diabetic patients: further clues to the etiology of diabetic neuropathy? Diabetologica 1992;35(12):1146-50.

[7] Sage RA, Webster JK, Fisher SG. Outpatient care and morbidity reduction in diabetic foot ulcers associated with chronic pressure callus. Journal of American Podiatric Medical Association 2001;91(6):275-9.

[8] Forrest KY, Maser RE, Pambianco G, et al. Hypertension as a risk factor for diabetic neuropathy: a prospective study. Diabetes 1997;46(4):665-70. 